\title{
Key success factors for a growing technology innovation system based on SMS Application-to-Person in Norway
}

\author{
Hanne Kristine Hallingby
}

Centre for Technology, Innovation and Culture, University of Oslo, Oslo, Norway

Telenor Research, Telenor, Fornebu, Norway

Telenor Research, Snarøyveien 30, N-1331 Fornebu, Norway, hanne-k.hallingby@ telenor.com, +47 91579213

\begin{abstract}
The case of SMS Application-to-Person in Norway documents how SMS has re-emerged as a significant channel for customer dialogue: SMS is increasingly used for everything from dentist appointments to communicating with tax authorities. The Technology Innovation Systems perspective is the basis for an assessment of inducement mechanisms for the case, and thus the critical success factors. More specifically, the case serves as an example of a platform-based business ecosystem where the ownership of the platform is shared and a core resource is provided by the mobile network operators. It is shown how the current growth of the SMS channel is founded on collective action in the system, and how the subsequent legitimation process has aligned the SMS channel with user expectations and practices. The actors' ability to collaborate and strike a balance between developing and sharing the market has been critical.
\end{abstract}

Keywords: SMS, technology innovation system, platform-based business ecosystem, legitimation, key success factors

\section{Introduction}

SMS-based mobile commerce used to be a growth field (Mylonopoulos and Doukidis 2003; Scornavacca and McKenzie 2007), however, the field took a different path. It is recognized that a shift came with smartphones (GSMA 2014; West and Wood 2013). Apple and Google took mobile commerce into the era of 
Web 2.0 and social media such as Facebook and Twitter (Kourouthanassis and Georgiadis 2014). New use of social media led to a stagnation of SMS for personto-person communication (Norwegian Communications Authority 2015), and has since challenged mobile network operators (GSMA 2014).

It is a puzzle why the market for SMS application-to-person (A2P) in Norway is growing by $25 \%$ annually according to figures released from the incumbent mobile network operator in Norway, end of 2014. SMS A2P is a submarket of the mobile industry and coordinates organisations' SMSs to their clients and customers; the messages sent through applications concern such things as appointment notifications, purchase statuses or flight information. To the knowledge of the author there is no documentation of how and why SMS A2P has started to grow in the shadow of new social media and communication channels. This paper therefore asks: what are the success factors of a rapidly growing SMS based mobile commerce ecosystem?

Previously, mobile commerce has been studied as socio-technical systems and ecosystems (Kourouthanassis and Georgiadis 2014; Kourouthanassis and Giaglis 2012; Mylonopoulos and Doukidis 2003). A holistic view that incorporates technology push, user demand and contextual aspects is recommended for analysing the complex and networked telecommunication technologies (Ghezzi, Rangone and Balocco 2013; Gao and Damsgaard 2007; Peppard and Rylander 2006). This resonates with the technological innovation system approach (TIS), which is a socio-technical systems perspective on how technology is developed, diffused and used (Bergek, Jacobsson, et al. 2008; Hekkert, Suurs, et al. 2007; Negro and Hekkert 2008). Also other more normative management theories explain market 
dynamics in industries that are systemic and interdependent, for instance platformbased business ecosystem (Gawer and Cusumano 2014; Gawer and Cusumano 2002) and ecosystems (Iansiti and Levien 2004; Moore 1993). In this paper TIS is the main theoretical lens to guide the search for explanations of the current growth of SMS A2P. It is useful due to the step-by-step analytic scheme, the focus on emergence of technologies, weight on technologies rather than firms and the stock of potential explanatory factors such as legitimation. However, platform-based theories are used to supplement the TIS approach.

The research contributes in three ways. First, it suggests new and reinforces explanations for diffusion and use of a networked and interdependent mobile technology application. Second, the platform approach used in the case adds to the TIS analytic scheme with a better understanding of the dynamics between technology platform and complements. Third, the TIS approach supplements the platform perspective by highlighting how platforms emerge and the role legitimation processes and collective dimension plays when taking an innovation system into a growth phase.

In the following section the research background and theory are described. Section three describes the method. In four and five the Norwegian market for SMS A2P is analysed. Section six discusses inducing and blocking mechanisms, policies and suggests theoretical contributions. The last section concludes.

\section{Background and theory}

\subsection{Growth of SMS A2P}

This case tries to explain the high growth of SMS A2P in Norway. Table 1 shows SMS A2P annual growth for the incumbent mobile network operator, Telenor. 
Telenor holds $50 \%$ of 6 million subscribers in Norway (Norwegian Communications Authority 2015). About 550 million SMSs were sent in Telenor's network in 2014, which implies that about 1.1 billion SMSs were sent from applications in 2014. In comparison about 6.1 billion SMSs were sent between persons (ibid.).

Table 1 Telenor SMS A2P traffic in Norway 2007-2014

\begin{tabular}{l|rrrrrrrr}
\hline & 2007 & 2008 & 2009 & 2010 & 2011 & 2012 & 2013 & 2014 \\
\hline $\begin{array}{l}\text { Traffic SMS } \\
\text { A2P, thousands }\end{array}$ & 79.093 & 167.284 & 209.598 & 246.583 & 301.064 & 362.714 & 443.079 & 557.280 \\
\hline Growth & & & & & & & \\
\hline
\end{tabular}

Source: Telenor Norway

\subsection{Theory and expectations}

The main theoretic approach in this paper is Technological innovation systems (TIS) (Bergek, Jacobsson, et al. 2008; Hekkert, Suurs, et al. 2007). TIS provides six steps that guide research and suggest explaining variables for growth (Bergek, Jacobsson, et al. 2008). First, technology and the greater innovation system it is part of, are defined. Second, the structural components actors, networks and institutions are identified, and how actors create value. Third, seven key innovation functions are described, and fourth, how well each system function is fulfilled (Hekkert, Negro, et al. 2011). At this point it is discussed how mature the innovation is, how far it has come in the 'emergence' phase, and status compared to other innovation systems. Fifth, inducing or blocking mechanisms are described and discussed. Sixth, based on the analysis, effective policies are outlined both from a societal and business perspective for further development, diffusion and use of the innovation in 
question.

TIS is a generic approach to understand the emergence of systemic technologies. Other theories more specifically explain dynamics for interdependent and networked technologies with a core player and complements, for instance platform-based business ecosystem (Gawer and Cusumano 2014; Gawer and Cusumano 2002) and ecosystems (Iansiti and Levien 2004; Moore 1993). Such platform approaches has been applied to analyze structure and dynamics in the mobile industry (Basole and Karla 2011; Peppard and Rylander 2006). A platform is: 'products, services or technologies developed by one or more firms, and which serve as foundations upon which a larger number of firms can build further complementary innovations and potentially generate network effects.' (Gawer and Cusumano 2014, 420). SMS A2P can be understood as a platform.

TIS is the focal approach in this paper, supplemented by the platform perspective. First, TIS provides a guide for empirical investigation with its steps and functions. Second, this analysis takes advantage of TIS' focus on technology rather than organizations, and technology as a result of collective action of several organizations (Hekkert, Negro, et al. 2011). In contrast, the platform approach mostly concerns one firm in control of one technology platform (Gawer and Cusumano 2014). The firm focus is also a major drawback of value network analysis (Peppard and Rylander 2006). According to West and Wood 'the platform literature has largely ignored the potential tensions of shared (or divided) platforms' (West and Wood 2013, 62), and recently Reuver et al (2014) have put challenges with shared ownership of a platform or technology on the agenda. 
Third, TIS focuses on the emergence of a technology. Much of the explanatory power of TIS' success and failure can be found by assessing seven innovation functions (Bergek, Jacobsson, et al. 2008) which alsoprovide sources for explanations that complement more normative platform theories. Gawer and Cusumano $(2014,27)$ recognize the need to develop better methods to assess emergence of a platform-based business ecosystems and call on 'concepts such as legitimacy, collective identity and institutional work'.

Fourth, TIS conveniently emphasizes institutions such as culture, norms and regulations (Bergek, Jacobsson, et al. 2008), and subsequent legitimation process which leads to the social acceptance and compliance with relevant institutions (Bergek, Jacobssen and Sandén 2008).

The above assessment of TIS and platform approaches reveal potential explanations for growth in SMS A2P. All the suggested TIS functions are sources for explanations, and a successful legitimation process is a necessary condition (Bergek, Jacobssen and Sandén 2008). The relationship between technology owners can explain failure (Reuver, et al. 2014) and success (Eaton, et al. 2014). Platformbased views provide best practices of how to regulate the relationship between the platform and its complements. Although acknowledging governance shortcomings (Boudreau and Haigiu 2009), sharing of revenues and risks is essential as well as giving access to platform via 'technical connectors' and open interfaces (Gawer and Cusumano 2014). Such connectors are hardly mentioned by the TIS approach. Finally, the significance of network effects is emphasized both by the TIS (Bergek, Jacobssen and Sandén 2008) and platform approaches (Gawer and Cusumano 2014; Boudreau and Haigiu 2009). Both perspectives acknowledge the significance of 
network externalities that have to do with advantages stakeholders take from shared and standard structures, resources and knowledge. However, platform perspectives put more weight to same-side and multisided network effects between the users of a platform as an explanatory factor (Boudreau and Haigiu 2009).

\section{Method}

The methodological approach in this paper is an explanation-building single case study (Yin 2014). The dependent variable is the growth of SMS A2P in Norway, and the research is aimed at exploring factors that can explain this growth. The use of TIS (Bergek, Jacobsson, et al. 2008) implies that the case study can be carried out in a more confirmatory way (Miles, Huberman and Saldaña 2014). Initial 'soaking and poking' with empirical data and theory (George and Bennett 2005) indicated that certain factors had more explanatory power, for instance legitimation and role balancing, and contributed to build a conceptual framework of the case study (Miles, Huberman and Saldaña 2014).

\subsection{Defining the innovation case}

SMS (Short Message Service) is a standard communication protocol developed for the mobile industry, first applied in 1992 (Hillebrand, et al. 2010). In line with Bergek et al. (2008) SMS A2P is a product - rather than a knowledge field - that is provided by mobile network operators as a platform. The spatial scope is Norway and time frame 2007-2016. The growth of SMS A2P is a phenomenon easy to isolate from stagnation of other SMS uses and the current growth of social media. Thus, it is also easier to identify explanatory factors. Even though previous work touches on factors that affect use and diffusion of SMS (Scornavacca and McKenzie 
2007; Peppard and Rylander 2006) the current distinction of the phenomenon can add strength to explanations.

Table 2 Data sources

\begin{tabular}{l|l}
\hline Data & Sources \\
\hline Market figures & Statistics SMS A2P: Telenor \\
& $\begin{array}{l}\text { General statistics: Norwegian Communications } \\
\text { Authority: web, direct communication. }\end{array}$ \\
\hline Aggregators & $\begin{array}{l}\text { Interviews: six senior executives/actors } \\
\text { Web-sites, press, accounting data (www.proff.no) }\end{array}$ \\
\hline Mobile network operators & $\begin{array}{l}\text { Telenor, incumbent: Interview Product manager, } \\
\text { Press Web-:prices, contractual documents }\end{array}$ \\
All operators: Press, Web-sites: prices, contractual \\
documents
\end{tabular}

\subsection{Data collection and analysis}

The data were collected in 2014-2016. Aggregators, a mobile operator, regulators and significant users were interviewed, and other sources of evidence collected such as documents and web-sites on regulations, contractual guidelines and technology 
descriptions (Yin 2014). Only the incumbent operator Telenor was interviewed ${ }^{1}$, however other types of data have been obtained from other operators. The responses from the incumbent were will only be elaborated on when they differ significantly. The semi-structured questionnaires were designed to illuminate explanations suggested by theories as well as capture new aspects. All interviews were recorded, transcribed and subject to open coding, however, aligned with the conceptual frameworks implicit in theoretical approaches (Miles, Huberman and Saldaña 2014). Coding was done in NVivo by the author.

\section{Structural components}

The TIS structural components are actors and institutions, and networks between them. The TIS for SMS A2P is well established with regards to institutions. SMS provisioning is regulated by Norwegian post- and telecommunication authorities, and the Consumer Council and Consumer Ombudsman regulate the use of SMS in customer dialogues and sale. SMSs paid by subscribers are measured by public authorities, while SMS A2P is not. The technology is mature and incorporated into research and education. The novel aspects of this TIS are the revitalised relevance of the technology and dynamics between the actors.

\subsection{New demand for SMS}

How private and public organizations are using SMS for messages to their customers and clients is exemplified in Table 3.

\footnotetext{
${ }^{1}$ The author is affiliated with this mobile operator.
} 
Efficient delivery of messages is important to firms and public bodies and can save costs, make operations more effective and increase customer satisfaction.

One actor holds that 'It is nowadays an expectation about getting a notification when the car is ready and can be picked up from the garage. You expect to get a message when something is not working according to schedule.'

Table 3 Examples SMS A2P use

\begin{tabular}{l|l}
\hline Firms and public bodies & Messages in customer and client dialogues \\
\hline & \\
Libraries, Dentists, Doctors, & Notifications, Appointment reminders, Delays, Shipment \\
Airlines, Hospitals, School & delays, Offerings, Discounts, Service renewals, Change \\
authorities, Trains, Banks, & requirements, Log-in passwords, Customer service \\
Utilities, Retailers, Clubs, & evaluations, Due dates, Statuses, News, Check-in data, \\
Online subscriptions & Verifications, Order confirmations, Warnings \\
\hline
\end{tabular}

Statistics Norway (2015) reports that $75 \%$ of the population sent an SMS, while only 39 used email on the mobile on an average day in 2015; this illustrates the general diffusion of SMS. The case study provides additional insight into why SMSs are used. Attributes 1-6 described in Table 4 signal network effects between users on both side of a market, as well as effects caused by evermore integration of mobile numbers into databases and systems dealing with customers and clients.

Table 4 Perceived SMS attributes

\begin{tabular}{l|ll}
\hline & SMS attribute & Explanations \\
\hline 1 & The mobile number & Everybody has a mobile number and accustomed to share it \\
2 & Reach and accuracy & SMS reaches any phone, anywhere, and only those relevant \\
\hline 3 & Authentication & ID of mobile user easy to confirm \\
4 & $\begin{array}{l}\text { Regulation: opt-in } \\
\text { and spam }\end{array}$ & $\begin{array}{l}\text { Spam is illegal, subject to fees. Opt-in and stop functionality } \\
\text { required. }\end{array}$ \\
5 & 'Codes' and format & High end-user skills and acceptance of for SMS A2P \\
\hline 6 & SMSs are read & 95\% of SMSs are read, most within 10 minutes
\end{tabular}




\begin{tabular}{c|lc}
7 & Simplicity & Mobile needs only to be on to receive SMS \\
\hline 8 & Effectiveness & Perceived value higher than cost \\
9 & Reports & Companies get a status of actual reception, and failures
\end{tabular}

\subsection{Actors and relationships}

The revitalising of SMS is intertwined with the emergence of a working business model. The actors and relationships are depicted in Figure 1 and illustrate how resources are combined to create value, and the role of each actor.

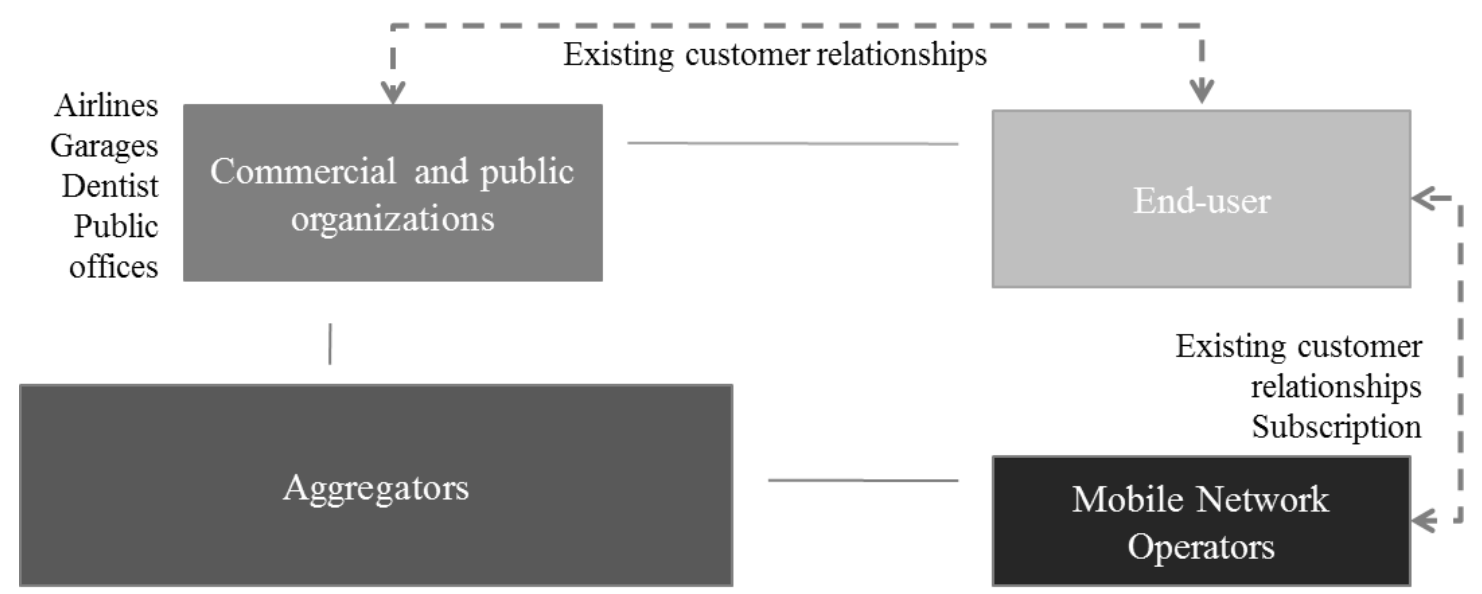

Figure 1 Actors and relationships in the SMS A2P TIS

The model depicted is not new in the telecom sector but serves to explain the setting for new growth. There are four core actors also described in Table 5: mobile network operator, aggregator, commercial or public organization, and enduser. Two important relationships are between end-user and mobile network operator and between end-user and a commercial and public organization.

The number of aggregators has stayed around 250 since 2007, mostly smaller firms. Each year one medium sized firm has entered the market. Several aggregators turned their firms around towards SMS A2P after the Smartphones and apps led to a stagnation of mobile content in 2008. The interviewed aggregators' 
revenues follow the market growth of SMS A2P; the return on investment (ROI) is more varied. Most of the aggregators had satisfying ROI in 2013; three of them were rated as very good. This gives an indication of a sound financial status of the SMS A2P business. Actors expect the market to grow with new types of utilization and smaller firms' uptake.

Table 5 Actors in the innovation system for SMS A2P

\begin{tabular}{|c|c|c|c|}
\hline Actors & Description & Number of actors & Market size \\
\hline $\begin{array}{l}\text { Mobile } \\
\text { network } \\
\text { operator }\end{array}$ & $\begin{array}{l}\text { Provide mobile } \\
\text { subscriptions to } \\
\text { End-users }\end{array}$ & 6 & $\begin{array}{l}6 \text { million subscribers } \\
1,1 \text { billion SMS A2P } \\
\text { Approx. NOK } 0,20 \text { per } \\
\text { SMS A2P, i.e. market is } \\
\text { NOK } 220 \text { mill. in total }\end{array}$ \\
\hline Aggregators & $\begin{array}{l}\text { Compile SMS } \\
\text { across mobile } \\
\text { operators and } \\
\text { resell } \\
\text { Integrate SMS } \\
\text { A2P into new } \\
\text { services }\end{array}$ & $\begin{array}{l}5-10 \text { larger actors } \\
250 \text { smaller actors in } \\
\text { total } \\
\text { Some global actors }\end{array}$ & $\begin{array}{l}\text { NOK } 220 \text { mill. plus } \\
\text { aggregator margins } \\
\text { Satisfying Return on } \\
\text { investment }\end{array}$ \\
\hline $\begin{array}{l}\text { Commercial } \\
\text { and public } \\
\text { organizations }\end{array}$ & $\begin{array}{l}\text { Buying and using } \\
\text { SMSs }\end{array}$ & $\begin{array}{l}\text { All firms and public } \\
\text { bodies in Norway }\end{array}$ & - \\
\hline End-user & $\begin{array}{l}\text { Mobile } \\
\text { subscribers. } \\
\text { Customers and } \\
\text { clients }\end{array}$ & $\begin{array}{l}5 \text { million inhabitants } \\
6 \text { million mobile } \\
\text { subscriptions }\end{array}$ & - \\
\hline
\end{tabular}

\subsubsection{Mobile operators' role}

The mobile operators' contribution to value creation is firstly the established base of mobile subscriptions which include SMS, and secondly giving other actors' access to the SMS A2P resource for further innovation. Access is given through a technological interface and commercial contracts. In general mobile network 
operators have a withdrawn role towards commercial and public organizations, also when it comes to innovation beyond core SMS A2P functionality; this is left to the aggregators and third parties. This withdrawn role is partly described as a necessary condition, however almost becoming too passive.

\subsubsection{Aggregators' role}

The aggregators have three main fields of value creation. First, they aggregate SMS functionality across mobile operators and resell a combined functionality. One aggregator explains: 'I guess that it is this, that is one of your assets, or your-you a kind of handle all this complexity, all these relationships, all the different mobile operators and make that into one unit'.

Second, the aggregators integrate the SMS A2P functionality into new advanced solutions. 'And that value creation - the additional value we put on the SMS enables a third party firm to receive a message from their customers, to process it, get it through the systems, and ensure that we deliver a functionality that is value-added', says one aggregator. The aggregators combine the SMS functionality with other qualified data. The data are processed for customer dialogue, which subsequently is documented and traceable.

Third, aggregators build operations that handle a volume SMS A2P market. This includes user friendly web-sites, dedicated salesforce and customer support. To the mobile operators SMS A2P is a niche product and not prioritized. As one aggregator puts it: 'All the sale and support activity has been done by the partners; that is actors like us. The mobile operators have one or two persons each, barely that, on their side.' 


\subsubsection{Actors' recognition of role}

The description of the SMS A2P core actors and their value creation signals clear recognition of roles. Furthermore, aggregators and mobile operators recognize high interdependency in several dimensions that serve as institutions regulating the market. In the first instance, operators have established shared approaches to the market between them, without violating competition laws and regulations (for instance application programming interfaces and grey traffic elimination).

In the second instance, the market is a balance between the aggregator and mobile network operators; they both want to make money at an acceptable risklevel. It is held as imperative that the mobile network operators keep away from the aggregator role.

One argument for balancing the market is that the mobile operators are dependent on the aggregators to innovate and invest: 'Because - yes, the operators must keep fingers off. If you want that variety - if we can call it that - in innovation. Right'. The value creation and selection processes driving innovation must not be obstructed by uncertainty about operators' intentions. Aggregators' willingness to invest will decrease if they risk competition from the operators, and one aggregator explains what happens where operators have not struck the balance: '... then they must change. So partners find it attractive to invest in development and innovation and sales based on them.' The aggregator adds that there worldwide are very few examples of such a well-functioning market as the Norwegian. The mobile operator has experienced that growth comes when aggregators take part in value creation, and is not threatened by the operator's competition. Also, a double role towards other operators could further complicate their joint effort to enable the market. 
The aggregators appreciate that operators are predictable and transparent. It comes through when the aggregators comment on the core attributes of the SMS channels (see Table 4), and prices. One aggregator elaborates on the significance of transparent pricing regime in the market: 'Equal treatment, you can say is an element in this. The incumbent has been very clear: OK, this is our price. If you send this much, you will get that price. And that applies to all. If you send for two million NOK it cost this much whether you are A or B. It gives a form of predictability. You are assured that a previous university acquaintance at the competitor does not get a better price than you. That would obstruct the competition - right? Neither does it create innovation.'

\subsubsection{Incentives and technological connectors between actors}

Innovation incentives are connected to economic incentives and price levels, one of the few areas where the interviewees divide. Aggregators describe SMS A2P as a monopoly resource controlled by mobile operators. Although prices seem to be harmonized across the operators, aggregators have a direct relationship to all in order to avoid 3-4 higher prices through the operators' interconnection agreements. All interviewees saw it as imperative that SMS A2P is based on a historic pricing system, and a price that signals its value compared to for instance 'free' email; furthermore, spam is deterred when the sender has to pay for the message. Half found the existing price level and division of revenues unfair; mobile operators' limited contribution to creation and operation of the market does not justify their share of revenues. The other half found that their own value creation made a difference that customers were willing to pay for in any case. However, it is recognized that the pricing system with incentives for the aggregators to innovate is 
a core element in this market. One aggregator says: 'I am convinced that if you want an innovative industry, and where all parts work to make the cake larger, then you need a model where there is something in it for all parts. I have zero confidence in those actors that make a solution where they themselves shall control everything. That is a fatal strategy, I think'. Some aggregators also reflect on a high fixed fee which favours larger aggregators, while this is operators' intention; operators want to avoid administering many small actors.

It is seen as critical that all mobile network operators give access to SMS A2P through technological connectors, however, not that it is identical across the operators. The aggregators even suggest that it would decrease their significance if the operators introduced highly standardized interfaces.

\subsection{Institutions}

Both formal regulations and agreements between the actors are held as prerequisites for the innovation system and the perceived attributes it produces for the actors. Thus, they can be considered as institutions within the innovation system. Number portability regulation and practices implemented in 2001 and mandatory IDrequirements for subscriber registration increase the strength of mobile number as consumer identifier and brand building for firms across mobile network operators (National Communication Authority 2015); it decreases risks when building systems and customer dialogues around the mobile number. 'The number portability, I would say, was a milestone. An important milestone for the value of SMS. Because then the mobile number becomes your ID - you carry it with you throughout your life - it is an important element.' says one aggregator. The database for numbers - Nasjonal referansedatabase - is jointly owned by network 
operators in Norway (Nasjonal referansedatabase 2015). The growing use and diffusion of the mobile number in systems and dialogues create network effects.

Mobile network operators coordinate short numbers for content; this fuelled the market, and thus end-users' accustoming to codes such as STOP and SEND in dialogues. 'It is a format that is introduced, accepted; ordinary people are starting to get accustomed to using code words.' says one aggregator.

The elimination of grey traffic (irregular traffic avoiding invoicing) is imperative for being able to claim a quality SMS service and charge a premium. One aggregator says: 'The closing of grey traffic that the large operators have done, has been important... It has been important to get rid of some actors that abuse the opportunities, and do not generate business neither to the operators nor the aggregators'. The incumbent's elimination already in 2007 set the market conditions and Norway is regarded as a pilot market in this field (Matthews 2015).

\section{Functional pattern of the TIS}

\subsection{Functional patterns and their goodness}

The TIS' behaviour can be characterized in terms of seven key innovation functions (Bergek, Jacobsson, et al. 2008). All in all the innovation function of the TIS is strong. In Table 6 the different functions for SMS A2P are assessed with regards to positive aspects that explain why the system is sound and potential negative aspects. To a large degree the foundation for this assessment is drawn from the above description of the structural components and therefore only summarily repeated in the table. 
The function Knowledge development is fulfilled in a good way due to the forward leaning aggregators, however with some potential drawbacks because mobile network operators are too passive.

Table 6 Summary assessment of TIS functions for SMS A2P

\begin{tabular}{|c|c|c|}
\hline Function & Positive for function & Negative for function \\
\hline $\begin{array}{l}\text { Knowledge } \\
\text { development }\end{array}$ & $\begin{array}{l}\text { Well known technology, business } \\
\text { dynamics give opportunities both for } \\
\text { aggregators and mobile network } \\
\text { operators } \\
\text { High recognition by aggregators, } \\
\text { aggregators are forward leaning and } \\
\text { competent }\end{array}$ & $\begin{array}{l}\text { Passive mobile network } \\
\text { operators } \\
\text { Market only partly measured } \\
\text { and reported by authorities and } \\
\text { actors }\end{array}$ \\
\hline $\begin{array}{l}\text { Search, } \\
\text { Experimentation, } \\
\text { Resource } \\
\text { mobilization, and } \\
\text { Market formation }\end{array}$ & $\begin{array}{l}\text { High growth rate among firms and } \\
\text { users } \\
\text { Growth beliefs: the smaller firms are } \\
\text { expected to start using SMS, } \\
\text { perceived positive SMS attributes } \\
\text { Aggregators explore alternatives, } \\
\text { turn crises around, are enthusiastic }\end{array}$ & $\begin{array}{l}\text { Potential deflation of SMS } \\
\text { through spam } \\
\text { Perceived price pressure } \\
\text { Aggregators are willing to } \\
\text { substitute } \\
\text { Passive mobile network } \\
\text { operators } \\
\text { Risk averse aggregators } \\
\text { Weak recruitment: mediocre } \\
\text { ROI and few new, well- } \\
\text { performing firms }\end{array}$ \\
\hline Legitimation & $\begin{array}{l}\text { Strong legislation } \\
\text { User learning processes } \\
\text { Large firms presence } \\
\text { Historic use of SMS } \\
\text { Spam in other channels }\end{array}$ & \\
\hline $\begin{array}{l}\text { Positive } \\
\text { externalities }\end{array}$ & $\begin{array}{l}\text { Mobile subscriber base attracts 'the } \\
\text { other side' - firms and public bodies } \\
\text { User «skills» and acceptance enhance } \\
\text { value to 'other side' } \\
\text { Strong functionality and knowledge } \\
\text { feedback loops between actors, high } \\
\text { degree of interdependence } \\
\text { Use and diffusion of mobile numbers } \\
\text { chosen as person identifier in in } \\
\text { market leading systems }\end{array}$ & $\begin{array}{l}\text { Potential deflation of SMS } \\
\text { through spam }\end{array}$ \\
\hline
\end{tabular}


Functions 2-4 and 6 are collapsed into one assessment; although the aggregators believe in market growth and explore alternatives they also report some risk factors such as threat of spam, price pressure, and too passive network operators. In addition, their willingness to explore includes investigating alternatives. These risk factors together with alternative attractive technologies can explain weak recruitment. Legitimation is discussed in detail below since it is found to have substantial positive effect on the status of the TIS. Likewise, there are positive externalities with regards to functional and knowledge aspects as well as network effects between user groups; however, spam can turn into a negative externality.

\subsection{Legitimation}

Legitimacy is a matter of social acceptance and compliance with relevant institutions (Bergek, Jacobssen and Sandén 2008). Legitimacy is not given; it is developed through a legitimation process.

The history of SMS as medium for communication between persons has legitimized it widely for receiving and sending messages. The current widespread use of other channels for private purposes such as Facebook messenger has indirectly turned SMS to a more formal channel. One aggregator explains that SMS used to be a private medium; the intrusion of a company message in this private sphere was unthinkable. This has changed completely. 'If we look ten years backor only six or seven years - then I would never have sent an SMS to a business acquaintance or someone I did not know in person. It was a more private channel. [...] Those limitations are completely gone. Now you can send SMS to anyone. There is nothing private about sending SMS. And I think more and more actors 
started to use the channel. You see the Tax Authorities use it, other public bodies use it. You have had some of these drivers that have legitimized the channel to a large degree’.

As mentioned above, the phenomenon of content provider access contributed to developing codes for communicating with SMS. The Consumer Ombudsman has together with mobile network operators developed a set of principles and tools ruling this field (Forbrukerombudet 2013 a), for instance specification of the code STOP to stop a service.

Large firms' use of SMS to communicate with customers has legitimized it. Mobile network operators have used SMS in their own customer service, and banks and public bodies to communicate with clients. Also this field has been subject to strict regulation, formally ruled under Norwegian legislation of marketing. The law is administered by the Consumer Ombudsman who provides principles for marketing via email, SMS etcetera (Forbrukerombudet 2013 b).The principles concern such things as approval, age, incentives, and type of use allowed. The Consumer Ombudsman has a digital interface for complaints and there is a fee for SMS-spam violating the principles. The aggregators are united in the importance of SMS regulation as a fundament for current and future position in communication. One aggregator puts it this way: 'And it is so ingenious that you are not allowed to spam. There are fees for spamming. It is very important that this is maintained. You have to ask for confirmation; you have to have opt-in for communicating. This is what makes it so incredibly good'. Although the legislation also rules e-mail and regulators treat them as identical it comes through that the mailbox is spammed to a 
much larger degree than SMS; this is held as one important attribute for SMS and the reason for why so many firms prefer SMS to the free e-mail.

The growth and legitimation of SMS A2P have taken place alongside the growth of social media such as Facebook, WhatsApp, and Twitter. This does not appoint SMS as better than other media, but rather illuminates the evolutionary process that accompanies the diffusion.

\subsection{Assessing the phase and comparative status of TIS}

The current high growth for SMS A2P justifies that it is in a take-off phase (Hekkert, Negro, et al. 2011). The actors perceive that the Norwegian growth is relatively high compared to the rest of Europe. This impression is supported by available predictions on 4-5\% global revenue growth (Transparency Market Research 2014; Juniper Research 2014). It is held as particularly important mobile operators in Norway are not aggregators, an explanation put forward for less growth in other countries.

Further explanation for a comparatively higher growth in Norway are an acceptable price level and effective price structure, early elimination of the grey traffic, advanced mobile market; pioneering firms, and trust in vendors and willingness to give away phone numbers. In general phone numbers are readily available in public databases.

\section{Discussion and conclusion}

In the TIS approach inducement and blocking mechanisms are those factors that are found to most affect functions. The mechanisms can be found in the `structural components of the emerging TIS and in the larger context surrounding it' (Bergek, 
Jacobsson, et al. 2008, 420), in this case described above. Figure 2 depicts the mechanisms found to mostly affect how well each functions is fulfilled.

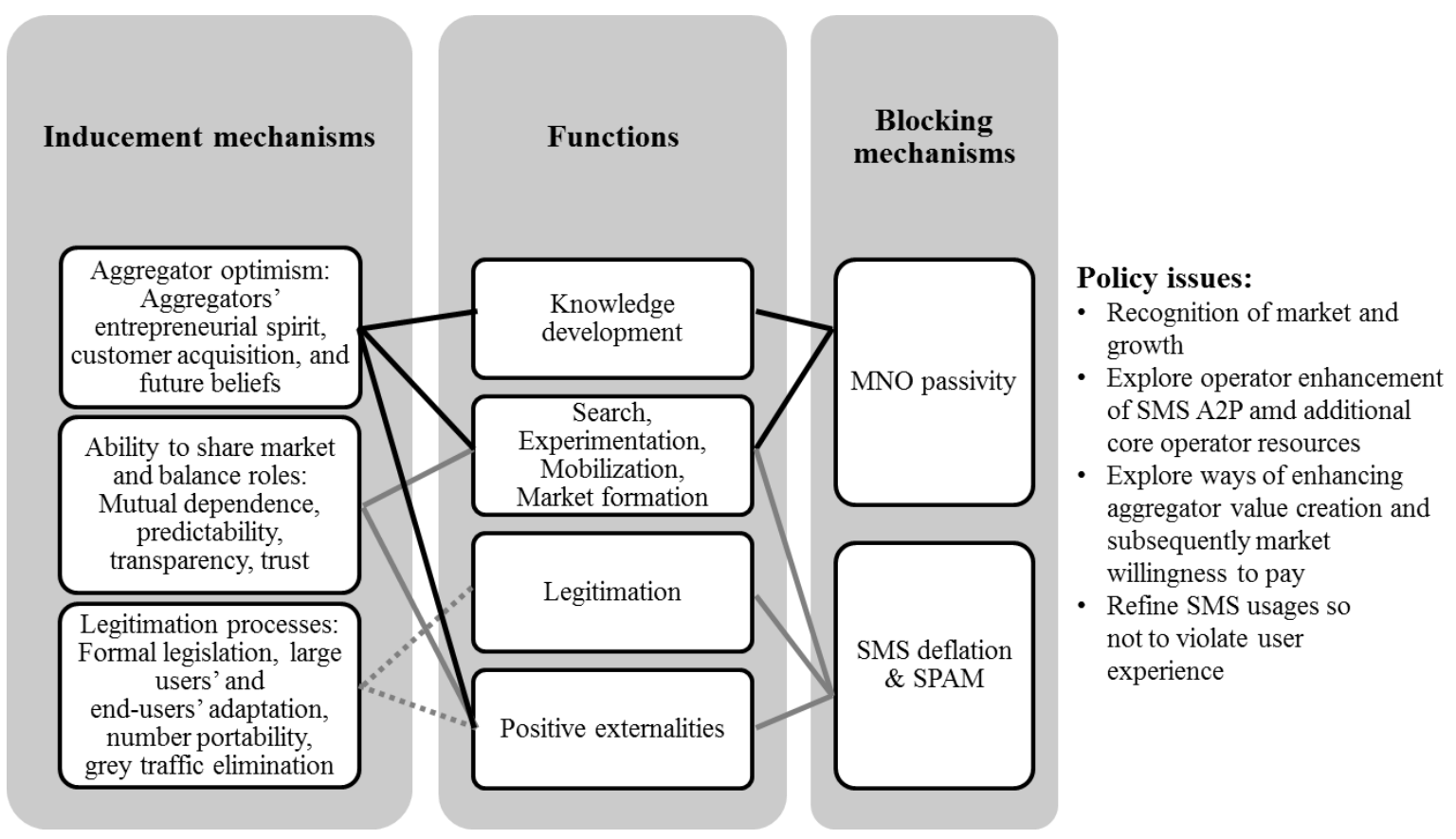

Figure 2 The TIS' inducement and blocking mechanisms, and policies

\subsection{Inducement mechanisms}

There are three major categories of inducement mechanisms that positively affect

SMS A2P. The first is aggregator optimism, a necessity for a system in a take-off phase (Hekkert, Negro, et al. 2011). Aggregators demonstrate an ability to experiment, innovate and acquire customers in their continuous recombination of SMS with other resources. History shows that they have turned crises around and have a positive belief in future opportunities. Both aggregators and mobile network operators acknowledge the role aggregators have in variety creation with SMS. It is the steady willingness to invest despite the more passive attitudes from the mobile operators in the market that is remarkable. It is a good thing that mobile operators are withdrawn; nevertheless, being too passive is described as a blocking 
mechanism below. The aggregators' accumulated insight into new applications and markets positively feeds the function knowledge development. It is their experimentation and - after all - optimistic future outlook that affect the good status of the TIS functions search, experimentation, and market formation.

The second inducement mechanism is the actors' ability to share market and balance roles; collaboration between the mobile network operators is one aspect of this. The value of SMS A2P is present only when all operators are included; thus, the platform ownership is shared. This is a challenge since operators continuously work to differentiate from others in order to attract end-users. The willingness to cooperate in the Norwegian market is not new. However, this aspect becomes more distinct when Norway is compared to other countries and firms' willingness to collaborate signals a climate of trust.

Aggregators have an important role for variety creation in the market; mobile operators are dependent on aggregators both to take the risk to scale innovation and market resources, and must share revenues with aggregators with adequate financial incentives. The mobile operators work to attract both end-users and aggregators in order to sustain the ecosystem, but have themselves a withdrawn role. To strike this balance is a challenge; both sides refer to trust based on predictability, shared revenues and transparency as key success factor in Norway compared to other markets and praise the other part.

This understanding of mutual dependence and ability to build trust positively affect belief in future market opportunities, risk taking and decisions to enter markets, and thus the functions search, experimentation and market formation. 
The subsequent strong system and knowledge feedback loops between actors lead to positive externalities.

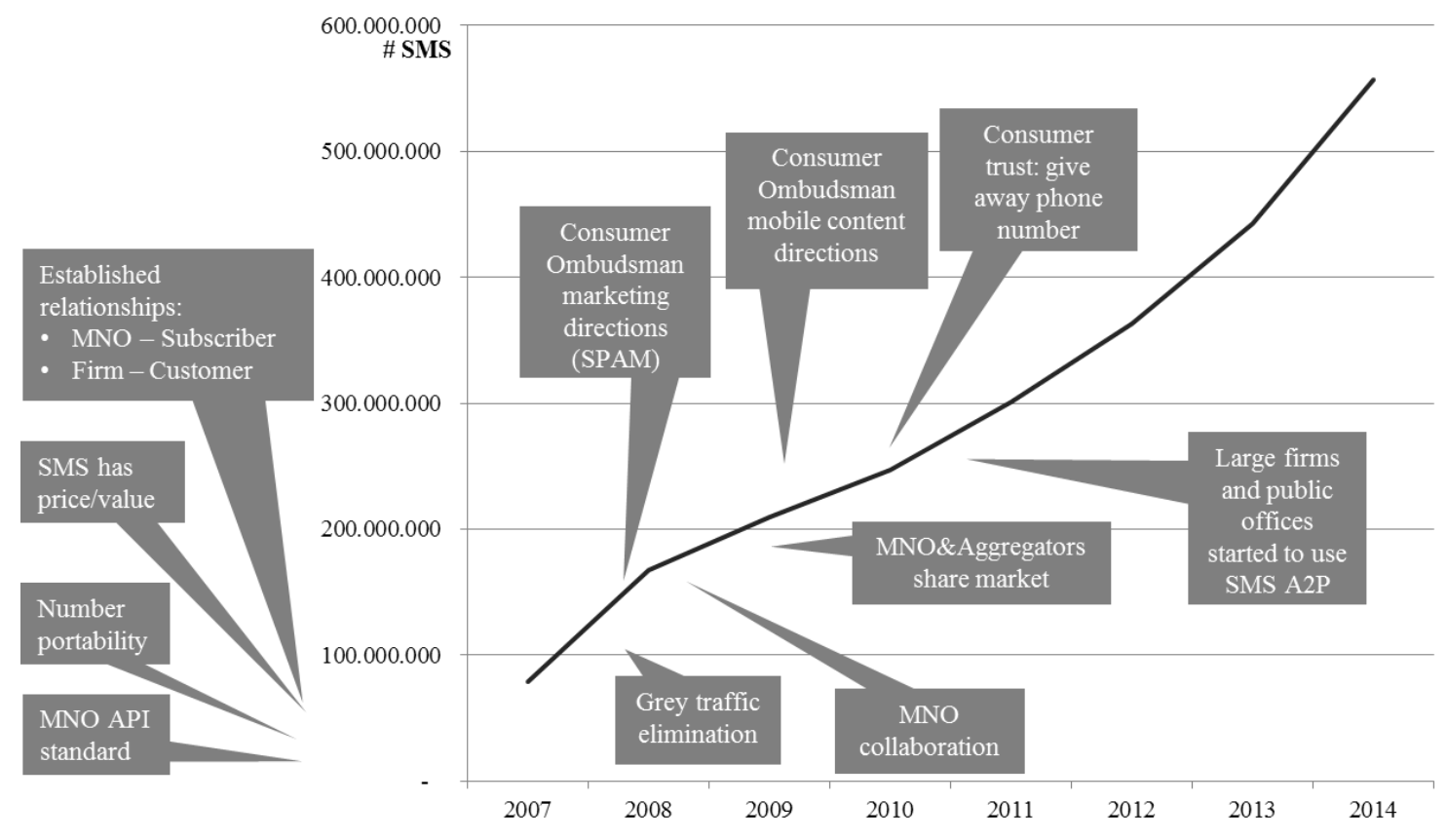

Figure 3 Growth process of SMS A2P in Norway 2007-2014

The third inducement category consists of processes that have led to a strong legitimation of use of SMS in communication between firms and users. This involves what now appear as institutions such as a shared understanding for SMScodes, mobile numbers as ID, and shared rules for dealing with grey traffic. Formal legislation and informal legitimation have affected how SMS is used. End-users' uptake of new channels for person-to-person communication and adaptation to large firms' use of SMS in customer interfaces have repositioned SMS. The increased use itself would lead to direct network effects, while the shared SMS practices and implementation of mobile numbers and SMS into market leading systems have strong positive network effects and further fuel the market growth. 
This indicates how legitimacy is formed, not given. Arguably, the collective willingness to share market and balance roles is a part of the legitimation process (Bergek, Jacobssen and Sandén 2008). This is all illustrated in Figure 3. Although the significance of legitimation is predicted by the TIS approach in this phase (Hekkert, Negro, et al. 2011) it is still surprising how actors emphasise this aspect when explaining success. They are all very positive when they refer to regulating formalities, and again the partaking from different actors in the processes (Bergek, Jacobssen and Sandén 2008). Altogether this positively affects legitimation, and also positive externalities.

\subsection{Blocking mechanisms and policies}

The withdrawn role of mobile operators is to some extent perceived as passivity and indicated to negatively affect the opportunity for further growth either it is due to not knowing or choosing not to get involved. Operators' passivity blocks further knowledge development, search, experimentation and market formation and can explain the low recruitment. Aggregators recognize the fine balance between themselves and operators but still call for operator involvement. Policies that could encounter these issues are clearer recognition of market significance, operators' enhancement of SMS A2P quality-of-service joint effort to increase the perceived value created in order to increase appropriability conditions for all actors.

A potential negative network effect is the possibility of SMS A2P turning into spam. The actors should jointly address how to increase SMSs sent without evoking end-users' negative perceptions. 


\subsection{Contribution to theory}

The case of SMS A2P in Norway contributes as middle-range theory (George and Bennett 2005) for a networked and interdependent technology. While the approaches of TIS and platform-based business ecosystem suggest generic factors that affect prosperity, this case suggests that especially three factors explains efficient innovation functions and platform growth in the telecom ecosystem: aggregator optimism, legitimation and balancing of roles. The importance of aggregator optimism is well founded in the TIS and platform approaches' weight on experimentation and sufficient incentives with regards to revenues and risks. The significance of legitimation and balancing of roles provide new insight to the field.

The case affirms the significance of the legitimation process suggested by Bergek, Jacobssen and Sandén (2008) while it adds insight to the platform literature. In the SMS TIS regulatory authorities, mobile operators, aggregators, large firms and governmental bodies have over time implemented contextual prerequisites, institutional frameworks and solutions that govern the current market. It has been a bottom-up evolutionary process and subsequent virtuous circle resulting in a growth of SMS A2P. The evolution has legitimized use of the service as well as its integration into systems operating the services. The latter has led to positive externalities predicted by both TIS and platform approaches. However, platform approaches mostly focus on network effects between users on multiple sides of the platform; thus, the significance of systems and knowledge feedback loops add to the platform approach. Notably, SMS also provide strong cross-side effects between third parties and end-users; the significance of such dynamics adds to the TIS approach. 
Furthermore, the actors clearly 'identify themselves as a part of a system, see the common problems and opportunities they face and the value of collective action' (Bergek, Jacobssen and Sandén 2008, 588). Collective action and shared technology ownership is at the core of TIS (Hekkert, Negro, et al. 2011), while the platform approach focuses on relationships between a single-owner platforms and its complements (Gawer and Cusumano 2014). Thus, the emphasis on overcoming tensions between platform owners to grow a market adds to the platform perspective. Recently this aspect has been suggested to explain both failures (Reuver, et al. 2014) and successes (Eaton, et al. 2014) of networked and interdependent technologies; Eaton et al. add that the Norwegian context is extraordinary trust-based, and climate of trust thus may serve as an underlying explanatory factor.

The significance of a balanced relationship with regards to revenues, risks, sale and customer services between the platform and complements is as expected by the platform perspective but adds to the dynamics described in the TIS approach. The case also refines the platform-based business ecosystem perspective on the necessity of standardized technical connectors. In the case it is held that the technical connector across the providers of the platform is critical but they must not be identical. Thus, one standardized connector is not a necessity to grow the market; however, it could still affect growth positively if present.

Finally, the case analysis proves how the TIS analytic scheme can add to platform approaches as a useful way to investigate emergence of a platform-based business ecosystem, better understand success and failure factors and potential intervening strategies. 


\section{Conclusion}

This paper explores the emergence and growth of SMS A2P in Norway. First, optimism among the aggregators in the system is important for growth. Second, aggregators and mobile network operators have been remarkably good at finding a balance between sharing the market, collaborating and competing; this is vital for willingness to invest and fuel off positive feedback loops. The collaboration between mobile network operators to provide core technology is specific for this case with shared platform ownership. Third, both formal and informal legitimation processes have been critical for developing the acceptance and skills for using SMS in customer relationships. Continued prosperity requires that mobile network operators recognize the significance of the market and take initiatives to enhance the SMS service further. Furthermore, actors should take joint actions to protect SMS from spam perceptions, and enable even more value created with SMS A2P. The research provides managers in the mobile industry with key success factors for networked and interdependent technologies where mobile network operators share and provide the core platform. From a theoretical perspective the research provides new insight to both the approaches TIS and platform-based business ecosystems. The TIS focus on collective action in innovations is enriched with understanding from the dynamics between platform and complements, as well as network effects between different user groups. The platform approach can draw on the weight TIS put on the legitimation processes, positive externalities for functions and knowledge, and a thorough analytic scheme for assessing how a technology emerge. 


\section{References}

Adner, Ron. "Introduction." In Collaboration and competition in business ecosystems, by Ron Adner, Joanne Oxley and Brian Silverman, ix-xviii. Bingley: Emerald group, 2013.

Basole, Rahul, and Jürgen Karla. "On the evolution of mobile platform ecosystem structure and strategy." Business \& Information Systems Engeneering 3, no. 5 (2011): 313-322.

Bergek, Anna, Staffan Jacobssen, and Bjørn Sandén. ""Legitimation" and "development of positive externalities": two key processes in the formation phase of technological innovation systems." Technology Analysis \& Strategic Management 20, no. 5 (2008): 575-592.

Bergek, Anna, Staffan Jacobssen, and Bjørn Sandén. "'Legitimation' and 'development of positive externalities': two key processes in the formation phase of technological innovation systems." Technology Analysis \& Strategic Management 20, no. 5 (2008): 575-592.

Bergek, Anna, Staffan Jacobsson, Bo Carlsson, Sven Lindmark, and Annika Rickne. "Analyzing the functional dynamics of technological innovation systems: A scheme for analysis." Research policy 37 (2008): 407-429.

Bergek, Anna, Staffan Jacobsson, Bo Carlsson, Sven Lindmark, and Annika Rickne. "Analyzing the functional dynamics of technological innovation systems: A scheme of analysis." Research policy 37 (2008): 407-429.

Boudreau, Kevin, and Andrei Haigiu. "Platform rules: multisided platforms as regulators." In Platforms, markets and innovation, by Annabelle Gawer, 163-191. Cheltenham: Edward Elgar Publishing Limited, 2009.

Eaton, Ben, Hanne Kristine Hallingby, Per-Jonny Nesse, and Ole Hanseth. "Achieving payoffs from an industry cloud ecosystem at BankID." MIS Quarterly Executive 13, no. 4 (December 2014): 223-235.

Forbrukerombudet. "Forbrukerombudets veiledning for fellesfakturerte tjenester [The Consumer Councils guide for services that are jointly invoiced]." Forbrukerombudet, May 2013 a.

—. "Forbrukerombudets veiledning om markedsføring via e-post, SMS o.l.markedsføringsloven $\S 15$ [The Consumer Council's guide for marketing via e-mail, SMS etc - Marketing law § 15].” Forbrukerombudet, January 2013 b.

Gao, Ping, and Jan Damsgaard. "A framework for understanding telecommunications market innovation: a case of China." Journal of electronic commerce research 8, no. 3 (2007): 184-195.

Gawer, A, and M. A. Cusumano. Platform leadership: How Intel, Microsoft, and Cisco drive industry innovation. Boston: Harvard Business School press, 2002.

-. Platform leadership: How Intel, Microsoft, and Cisco drive industry innovation. Boston: Harvard Business School press, 2002.

Gawer, Annabelle, and Michael A Cusumano. "Industry platforms and ecosystem innovation." Journal of product innovation management 31, no. 3 (2014): 417-433. 
Gawer, Annabelle, and Rebecca Henderson. "Platform owner entry and innovation in complementary markets: Evidence from Intel." Journal of Economics and Management Strategy 16, no. 1 (2007): 1-34.

George, Alexander, and Andrew Bennett. Case studies and theory development in the social sciences. Cambridge: MIT Press, 2005.

Ghezzi, Antonio, Andrea Rangone, and Raffaello Balocco. "Technology diffusion theory revisited: a regulation, environment, strategy, technology model for technology activation analysis of mobile ICT.” 25, no. 10 (2013): 12231249.

GSMA. “API-Exchange-2014-11_online-version5.” www.gsma.com. 1 November 2014. http://www.gsma.com/oneapi/wp-content/uploads/2014/12/APIExchange-2014-11_online-version5.pdf (accessed June 18, 2015).

GSMA. Business models for network APIs. London: GSMA, 2013.

—. The mobile economy 2013. London: GSMA and AT Kearney, 2014.

GSMA. The mobile economy 2014. London: GSMA, 2014.

GSMA. The value of Operators APIs for developers - White paper. London: GSMA, 2014.

Hekkert, Marko, Roald Suurs, Simona Negro, Stefan Kuhlman, and Ruud Smits. "Functions of innovation systems: a new approach for analysing technological change." Technological Forecasting \& Social Change, 2007: 413-432.

—. "Functions of innovation systems: a new approach for analysing technological change." Technological Forecasting \& Social Change, 2007: 413-432.

Hekkert, Marko, Simona Negro, Gaston Heimeriks, and Robert Harmsen.

"Technological innovation system analysis: A manual for analysts."

www.innovation-system.net. Faculty of geosiciences, Copernicus instiute for sustainable development and innovation. November 2011.

http://www.innovation-system.net/wpcontent/uploads/2013/03/UU_02rapport_Technological_Innovation_System _Analysis.pdf (accessed February 17, 2015).

Hillebrand, Friedheim, Finn Trosby, Kevin Holley, and Ian Harris. Short message service (SMS); The creation of a personal global text messaging.

Chichester: John Wiley \& Sons, 2010.

Iansiti, M, and R Levien. The keystone advantage. What the new dynamics of business ecosystems mean for strategy, innovation and sustainability. USA: Harvard Business School press, 2004.

Juniper Research. "Press Release: A2P messaging worth almost $\$ 60$ bn by 2018, driving overall SMS revenues, Juniper Researh finds." www.juniperresearch.com. 7 May 2014. http://www.juniperresearch.com/viewpressrelease.php?pr=444 (accessed November 4, 2014).

Kourouthanassis, Panos, and Christos Georgiadis. "Analysing m-commerce research: technology, applications and research themes." International journal of mobile communications 12, no. 1 (2014): 1-11.

Kourouthanassis, Panos, and George Giaglis. "Introduction to the special issue: The past, present, and future of mobile commerce research." International journal of electronic commerce 16, no. 4 (2012): 5-18. 
Matthews, Guy. "SMS special report: Confronting SMS fraud." Capacity Media. 26 August 2015. http://www.capacitymedia.com/Article/3483282/Home/SMSSPECIAL-REPORT-Confronting-SMS-fraud.html (accessed January 15, 2016).

Miles, Matthew, Michael Huberman, and Johnny Saldaña. Qualitative analysis: a methods sourcebook. Los Angeles: SAGE Publications, 2014.

Moore, James. "Predators and prey: a new ecology of competition." Harvard Business Review, May-June 1993: 75-86.

Mylonopoulos, Nikolas, and Georgios Doukidis. "Introduction to the special issue: Mobile business: technology pluralism, social assimilation, and growth." International journal of electronic commerce 8, no. 1 (2003).

Nasjonal referansedatabase. Om oss [About us]. 17 June 2015. http://nrdb.no/omoss/.

National Communication Authority. Flytting av nummer mellom tilbydere (nummerportabilitet) [Moving phonenumbers between providers (number portability)]. 17 June 2015.

http://www.nkom.no/teknisk/nummerforvaltning/nummerforvaltning/flyttin g-av-nummer-mellom-tilbydere-nummerportabilitet.

—. Flytting av nummer mellom tilbydere (nummerportabilitet). 17 June 2015. http://www.nkom.no/teknisk/nummerforvaltning/nummerforvaltning/flyttin g-av-nummer-mellom-tilbydere-nummerportabilitet.

Negro, Simona, and Marko Hekkert. "Explaining the success of emering technologies by innovation system functioning: the case of biomass in Germany." Technology Analysis \& Strategic Management 20, no. 4 (2008): 465-482.

Norwegian Communications Authority. Det norske markedet for elektroniske kommunikasjonstjenester 2014 [The Norwegian market for electronic communication services]. Lillesand: Norwegian Communications Authority, 2015.

Peppard, Joe, and Anna Rylander. "From value chain to value network: Insights for mobile operators." European Management Journal 24, no. 2-3 (2006): 128141.

Perrons, Robert. "The open kimono: How Intel balances trust and power to maintain platform leadership." Research Policy 38 (2009): 1300-1312.

Reuver, Mark de, Edgar Vershuur, Fatemeh Nikayin, Narciso Cerpa, and Harry Bouwman. "Collective action for mobile payment platforms: A case study on collaboration issue between banks and telecom operators." Electronic commerce research and applications 14 (2014): 331-344.

Scornavacca, Eusebio, and Jonathon McKenzie. "Unveiling managers' perceptions of the critical success factors for SMS based campaigns." International journal of mobile communications 5, no. 4 (2007): 445-456.

Statistics Norway . Statistic bank: Table: 05242: Share that have used electronic offerings and number of private phone calls an average day. 2015. https://www.ssb.no/statistikkbanken - open log in solution (accessed January 19, 2016).

Transparency Market Research. "A2P SMS market expected to reach USD 70.32 Billion in 2020." www.transparencymarketsresearch.com. 14 October 2014. 
http://www.transparencymarketresearch.com/pressrelease/a2p-smsmarket.htm (accessed November 4, 2014).

West, Joel, and David Wood. "Evolving an open ecosystem: the rise and fall of the Symbian platform." In Collaboration and competition in business ecosystems, by Ron Adner, Joanne Oxley and Brian Silverman, 27-68. Bingley: Emerald group, 2013.

Yin, Robert. Case study research. Design and methods. Beverly Hills: Sage publications, 2014. 